\title{
Effects of guanylurea, the transformation product of the antidiabetic drug metformin, on the health of brown trout (Salmo trutta f. fario)
}

\author{
Stefanie Jacob ${ }^{\text {Corresp., } 1}{ }^{\text {, Sarah Knoll }}{ }^{2}$, Carolin Huhn ${ }^{2}$, Heinz-R. Köhler ${ }^{1}$, Selina Tisler ${ }^{3}$, Christian Zwiener ${ }^{3}$, Rita \\ Triebskorn $^{1,4}$ \\ 1 University of Tübingen, Animal Physiological Ecology, Tübingen, Germany \\ 2 University of Tübingen, Effect-based Environmental Analysis, Tübingen, Germany \\ 3 University of Tübingen, Environmental Analytical Chemistry, Tübingen, Germany \\ 4 Steinbeis Transfer Center for Ecotoxicology and Ecophysiology, Rottenburg, Germany \\ Corresponding Author: Stefanie Jacob \\ Email address: stefanie.jacob@uni-tuebingen.de
}

Background. Guanylurea is the main transformation product of the antidiabetic drug metformin which belongs to the top prescribed pharmaceuticals worldwide. Due to a high rate of microbial degradation of metformin in sewage treatment plants, guanylurea occurs in higher concentrations in surface waters than its parent compound and could therefore affect aquatic wildlife. In this context, data for fish are scarce up to now which made us investigate the health of brown trout (Salmo trutta f. fario) in response to guanylurea.

Methods. In two experiments, eggs plus the developing larvae and juvenile brown trout were exposed to three different concentrations of guanylurea $(10,100,1000 \mu \mathrm{g} / \mathrm{L})$ and, as a negative control, filtered tap water without this compound. Low internal concentrations were determined. The investigated parameters were mortality, length, weight, condition factor, tissue integrity of liver and kidney, levels of stress proteins and lipid peroxides, as well as behavioural and developmental endpoints. It was shown that guanylurea did not significantly change any of these parameters in the tested concentration range.

Results. In conclusion, these results do not give rise to concern that guanylurea could negatively affect the health or the development of brown trout also under field conditions. Nevertheless, more studies focusing on further parameters and other species are highly needed for a profound environmental risk assessment of guanylurea. 
1 Effects of guanylurea, the transformation product of the antidiabetic

2 drug metformin, on the health of brown trout (Salmo trutta f. fario)

3 Stefanie Jacob ${ }^{1}$, Sarah Knoll2 , Carolin Huhn², Heinz-R. Köhler ${ }^{1}$, Selina Tisler ${ }^{3}$, Christian

4 Zwiener ${ }^{3}$, Rita Triebskorn ${ }^{1,4}$

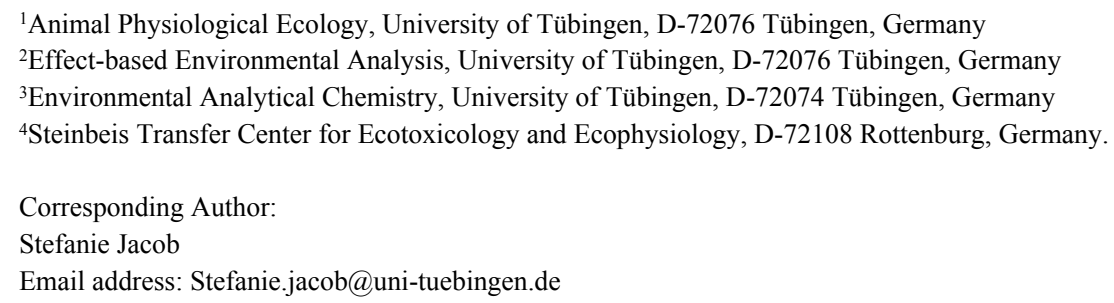

\section{Abstract}

14 Background. Guanylurea is the main transformation product of the antidiabetic drug metformin which belongs to the top prescribed pharmaceuticals worldwide. Due to a high rate of microbial degradation of metformin in sewage treatment plants, guanylurea occurs in higher concentrations in surface waters than its parent compound and could therefore affect aquatic wildlife. In this context, data for fish are scarce up to now which made us investigate the health of brown trout (Salmo trutta f. fario) in response to guanylurea.

Methods. In two experiments, eggs plus the developing larvae and juvenile brown trout were exposed to three different concentrations of guanylurea $(10,100,1000 \mu \mathrm{g} / \mathrm{L})$ and, as a negative control, filtered tap water without this compound. Low internal concentrations were determined. The investigated parameters were mortality, length, weight, condition factor, tissue integrity of liver and kidney, levels of stress proteins and lipid peroxides, as well as behavioural and developmental endpoints. It was shown that guanylurea did not significantly change any of these parameters in the tested concentration range.

Results. In conclusion, these results do not give rise to concern that guanylurea could negatively affect the health or the development of brown trout also under field conditions. Nevertheless, more studies focusing on further parameters and other species are highly needed for a profound environmental risk assessment of guanylurea.

\section{Introduction}

32 For environmental risk assessment of chemicals, the inclusion of transformation products and the investigation of their contribution to the risk posed by the parent compound are often challenging and increase the complexity of the evaluation process. In this context, it is a major issue that the identity of transformation products is often unknown, in addition, there is a general dearth of data concerning the ecotoxicological effects of identified ones (Celiz et al. 2009). However, 
and toxicity than their parent compound, it would be a striking error to neglect transformation products in risk assessment (Escher \& Fenner 2011). For example, Schlüter-Vorberg et al. (2015) showed that carboxy-acyclovir, a transformation product of the antiviral drug acyclovir formed in sewage treatment plants, was much more toxic than its parent compound. Valsartanic acid, the transformation product of the antihypertensive drug valsartan formed in the activated sludge of waste water treatment plants, was shown to be much more persistent than its parent compound (Berkner \& Thierbach 2014; Helbling et al. 2010). An example for a transformation product with a high formation yield is guanylurea. The substance is generated in sewage treatment plants by microbial degradation of the antidiabetic drug metformin (Scheurer et al. 2012; Tisler \& Zwiener 2018; Trautwein \& Kümmerer 2011) and is detected in surface waters at concentrations up to 28 $\mu \mathrm{g} / \mathrm{L}$ (Scheurer et al. 2012), whereas the maximum concentration of the parent compound is about a factor of 10 smaller (Scheurer et al. 2012). Generally, data on the ecotoxicity of guanylurea are scarce (Riegraf et al. 2017). To the best of our knowledge, there is only a single study addressing the effects of guanylurea in fish. In this study, larval Japanese medaka (Oryzias latipes) were exposed test to $1-100 \mathrm{ng} / \mathrm{L}$ guanylurea for 28 days in an early life stage resulting in significantly reduced growth at all tested concentrations (Ussery et al. 2019). Mortality, time to hatch, and hatching success were not influenced by the chemical. In the same study of Ussery et al. (2019), growth was not significantly reduced in adult medaka exposed to $1 \mathrm{ng} / \mathrm{L}$ and $7.5 \mu \mathrm{g} / \mathrm{L}$ guanylurea in a full life cycle test. In addition, the authors reported that the hormonal system seemed to be influenced by guanylurea, since enhanced estradiol production was measured in the liver of male adult medaka exposed to $7.5 \mu \mathrm{g} / \mathrm{L}$ guanylurea. There are few studies dealing with the effects of guanylurea in invertebrates. In crustaceans, a low sensitivity to guanylurea was shown: Daphnia magna was immobilized with a $50 \%$ effective concentration $\left(\mathrm{EC}_{50}\right)$ value of 40 $\mathrm{mg} / \mathrm{L}$ (Markiewicz et al. 2017). In another study, reproduction of Ceriodaphnia dubia remained unaffected with a no observed effect concentration (NOEC) of $8 \mathrm{mg} / \mathrm{L}$ (Caldwell et al. 2019). In our study, we investigated whether and how guanylurea influences the development and health of brown trout (Salmo trutta f. fario), a species of high environmental relevance for Central Europe, at several organisational levels. Studies were conducted with larvae developed from exposed eggs and nine month-old juvenile fish exposed for three weeks to cover sensitive life stages of the selected species. The investigated parameters were apical endpoints as mortality, body weight and length, condition factor, as well as the time to hatch and heart rate of the larvae to account for embryotoxicity. Moreover, we investigated the tissue integrity of the most important organs in metabolism and biotransformation - liver and kidney, since histopathology is a good marker to detect sublethal effects of chemicals on cells and organs (Bernet et al. 1999; Johnson et al. 1993; Schwaiger et al. 1992; Triebskorn et al. 2007). As general, biochemical stress markers, the level of the $70 \mathrm{kDa}$ heat shock protein family (Hsp70) was analysed in the head of juvenile brown trout and the lipid peroxide level was measured in the head of larval brown trout. Hsp70 induction is part of the molecular stress response which is highly conserved across a wide range of taxa (Margulis et al. 1989). Their function lies in the folding of nascent proteins and the re-folding of partially damaged proteins. Lipid peroxides are 
the product of reactions of reactive oxygen species (ROS) with polyunsaturated lipids (Monserrat et al. 2003). ROS are generated by different biochemical processes, e.g. by aerobic respiration or the metabolism of xenobiotics (Betteridge 2000; Valavanidis et al. 2006). In case of an imbalance between the ROS production and the anti-oxidative defence, oxidative stress can arise (Betteridge 2000). For example, alterations of the membrane fluidity in mitochondria caused by lipid peroxides (Chen \& Yu 1994) can lead to a loss of essential cellular functions (Hermes-Lima et al. 1995). The parent compound of guanylurea, the antidiabetic drug metformin, was shown to decrease the stress protein level (Piro et al. 2012). Concerning the effects of the pharmaceutical on oxidative stress, the literature stated metformin to be able to reduce (Anurag \& Anuradha 2002; Bonnefont-Rousselot et al. 2003) but also increase (Dai et al. 2014; Lee et al. 2019) the level of oxidative stress. Therefore, we wanted to investigate whether guanylurea has similar effects on the Hsp70 and lipid peroxide level as its parent compound. Additionally, for the juvenile brown trout, the swimming behaviour (total distance moved and mean velocity) was analysed, since physiological stress may manifest itself in behavioural alterations (Scott \& Sloman 2004). The parent compound metformin is known to influence the aggression behaviour of Siamese fighting fish (Betta splendens). Thus, we wanted to know whether guanylurea is able to change the movement activity of brown trout. Finally, the uptake of guanylurea into the tissue of the brown trout larvae was determined.

\section{Material and Methods}

\section{Test organisms}

Brown trout (Salmo trutta f. fario) were purchased from a commercial fish breeder (trout breeding Lohmühle, D- 72275 Alpirsbach-Ehlenbogen) whose fish breeding is listed as category I, disease-free according to the EC Council Directive (EU 2006). Eggs in the eyed-ova stage (46 days post fertilisation (dpf)) were exposed directly after purchase. Juvenile fish (age: nine month) were kept in a $250 \mathrm{~L}$ aquarium in the laboratory for two weeks prior to the exposure experiments for acclimation to the lab conditions.

\section{Test substances}

Guanylurea sulphate (CAS number: 591-01-5; Lot: WIA7F and AKJLG; purity: 98 \%) was purchased from Tokyo Chemical Industry (Tokyo, Japan). With a maximum solubility in water of $50 \mathrm{~g} / \mathrm{L}$ (ChemIDplus), the substance was readily soluble in water. The concentrations of guanylurea investigated in the present study refer to the free base.

\section{Exposure experiments and sampling}

\section{Larval brown trout}

Eyed eggs of brown trout ( $46 \mathrm{dpf}$ ) were exposed to four different nominal concentrations of guanylurea $(0,10,100$ and $1000 \mu \mathrm{g} / \mathrm{L})$ in triplicate at $7{ }^{\circ} \mathrm{C}$ in a climate chamber (start: Dec 29, 2017). The exposure was conducted in a semi-static system using glass aquaria with 30 test 
114 organisms per $10 \mathrm{~L}$ test medium. After 91 days of exposure, the water volume was increased to

$11515 \mathrm{~L}$ per aquarium. In total, 360 individuals were investigated for their development and health.

116 During the experiment, hatching and mortality were recorded daily. At day 40, when the larvae

117 reached the finfold resorption phase (step 38/39 according to Killeen et al. (1999)), the heart rate

118 was determined. Fifteen larvae (five per replicate aquarium) from both the control and the 1000

$119 \mu \mathrm{g} / \mathrm{L}$ guanylurea treatment were transferred to vessels containing the respective test medium and

120 the heart rate of each individual was counted for $20 \mathrm{~s}$. Twice a week, $50 \%$ of the exposure

121 medium was exchanged with freshly prepared medium. Aerated and filtered tap water (iron

122 filter, active charcoal filter, particle filter) was used for the preparation of the medium. The

123 medium in the aquaria was aerated with air stones (JBL Pro Silent Aeras Micro S2). The

124 illumination conditions were kept constant during the test with a $10 \mathrm{~h} / 14 \mathrm{~h}$ - light/dark cycle.

125 Additionally, the aquaria were shaded from direct light using black plastic foil. After yolk-sac

126 consumption (day 56), the larvae were fed every day with commercial trout food (INICIO plus

$1270.5 \mathrm{~mm}$ from Biomar, Denmark). The amount of food provided per day was constantly adapted

128 in relation to the developmental status of the brown trout; the larvae were fed at maintenance.

129 During the water exchange process, excess food and faeces were removed. Temperature, $\mathrm{pH}$,

130 oxygen content and conductivity were monitored at the beginning and end of the test as well as

131 at day 55 (temperature $=7.3 \pm 0.2{ }^{\circ} \mathrm{C}, \mathrm{pH}=8.33 \pm 0.05$, oxygen concentration $=11.00 \pm 0.20 \mathrm{mg} / \mathrm{L}$,

132 conductivity $=483 \pm 15 \mu \mathrm{S} / \mathrm{cm})$. Eight weeks after yolk-sac consumption (17.04.2018; after 110

133 days) the fish were euthanised with an overdose of MS $222\left(1 \mathrm{~g} / \mathrm{L}\right.$ buffered by $\left.\mathrm{NaHCO}_{3}\right)$ and

134 subsequent severance of the spine. Length and weight of fish as well as possible abnormalities or

135 injuries were recorded. Fulton's condition factor was calculated (ratio of weight and length

136 cubed). Due to the small size of the test organisms, individual fish were separated into three

137 groups (samples obtained from 10 individuals per replicate aquarium; 30 individuals per

138 treatment). In the first group, the liver was sampled for histopathological examination. The

139 second group provided samples for the analyses of lipid peroxide level (head). In the third group,

140 samples for chemical analysis of fish tissue were gained; for this purpose, the middle part of the

141 fish was used (tissue between neck and dorsal fin). Samples for histological analysis were

142 chemically fixed in glutardialdehyde. All other samples were immediately frozen in liquid

143 nitrogen and stored at $-80^{\circ} \mathrm{C}$ until further analysis.

\section{Juvenile brown trout}

145 Juvenile brown trout (age: nine month) were exposed to four different nominal concentrations of

146 guanylurea $(0,10,100$ and $1000 \mu \mathrm{g} / \mathrm{L})$ in triplicate at $7{ }^{\circ} \mathrm{C}$ in a climate chamber. The exposure

147 was conducted in a semi-static system using glass aquaria with ten test organisms per $15 \mathrm{~L}$ test

148 medium. In total, 120 individuals were investigated. The water exchange and the illumination

149 conditions were the same as described above. Daily, juvenile brown trout were fed a defined

150 amount of commercial trout food (INICIO plus $0.8 \mathrm{~mm}$ from Biomar, Denmark). Temperature,

$151 \mathrm{pH}$, oxygen content and conductivity of the media in the aquaria were monitored at the beginning

152 and end of the test (temperature $=6.9 \pm 0.3{ }^{\circ} \mathrm{C}, \mathrm{pH}=8.33 \pm 0.12$, oxygen concentration $=11.42 \pm$

$1530.15 \mathrm{mg} / \mathrm{L}$, conductivity $=497 \pm 23 \mu \mathrm{S} / \mathrm{cm})$. After 29 days of exposure (08.08.2017-05.09.2017), 
154 seven fish per aquarium (21 per treatment) were euthanised with an overdose of MS $222(1 \mathrm{~g} / \mathrm{L}$

155 buffered by $\mathrm{NaHCO}_{3}$ ) and subsequent severance of the spine. Length and weight of fish, as well

156 as possible abnormalities or injuries, were recorded. Liver and kidney were sampled for

157 histopathological examination. The head was taken for the analysis of the stress protein level.

158 Samples for histological analyses were chemically fixed in glutardialdehyde. All other samples

159 were immediately frozen in liquid nitrogen and stored at $-80{ }^{\circ} \mathrm{C}$. The remaining three fish per

160 aquarium (nine per treatment) were used for swimming behaviour experiments (Sep 07, 2017).

161 In addition to the negative control in the lab, 20 juvenile brown trout were sampled directly at the

162 trout breeding facility as a qualitative "hatchery control" (Sep 12, 2017).

\section{Chemical analyses}

164 During the experiments, water samples were taken to determine the real guanylurea

165 concentrations in the test medium. For both experiments, water samples were taken at the

166 beginning (larvae: Dec 29, 2017; juveniles: Aug 08, 2017) and end of the experiment (larvae:

167 Apr 17, 2018; juveniles: Sep 05, 2017). Moreover, samples were taken during the exposure,

168 before and after water exchange (larvae: after 25, 56 and 77 days; juveniles: after 14 days). The

169 samples were stored at $-20^{\circ} \mathrm{C}$ until further processing. At the end of the experiment, tissue

170 samples of the brown trout larvae (between neck and dorsal fin) containing liver, muscle, gut and

171 kidney were investigated to determine the internal guanylurea concentration in the fish.

\section{Analysis of water concentrations by LC-MS}

173 The real water concentrations were determined using LC-MS with a 1290 Infinity HPLC system

174 (Agilent Technologies, Waldbronn, Germany) and a quadrupole time of flight mass spectrometer

175 (6550 iFunnel QTOF, Agilent Technologies, Santa Clara, CA, USA). For separation, a

176 Phenomenex LUNA 5 u HILIC 200 A column $(150 \times 3 \mathrm{~mm} ; 5 \mu \mathrm{m}$ particle size $)$ with a flow rate

177 of $0.5 \mathrm{~mL} / \mathrm{min}$ at $40{ }^{\circ} \mathrm{C}$ was used. A gradient elution was performed with eluent A (aqueous

178 buffer with $15 \mathrm{mM}$ ammonium formate and $0.1 \%$ formic acid) and eluent $\mathrm{B}$ (acetonitrile with

$1790.1 \%$ formic acid) (all chemicals purchased from Fisher Scientific, Schwerte, Germany). A

180 portion of $95 \%$ of eluent B was used for $0-4 \mathrm{~min}$, decreased to $50 \%$ within 4 min and held for 6

$181 \mathrm{~min}$. After switching back to the starting conditions, post time was $8 \mathrm{~min}$.

182 Samples were kept in the autosampler at $10{ }^{\circ} \mathrm{C}$. The injection volume was $20 \mu \mathrm{L}$. All samples

183 had a composition of $90 \%$ acetonitrile and $10 \% \mathrm{H}_{2} \mathrm{O}$ due to dilution with acetonitrile. The

184 ionisation of guanylurea was performed in the positive ionisation mode. Further details on

185 operating parameters of the QTOF are provided in the Supplement (Paragraph S1, Table S1).

186 Acquired data were processed with the software Mass Hunter (Agilent Technologies). For

187 quantification and confirmation, the exact mass of guanylurea $[\mathrm{M}+\mathrm{H}]^{+} \mathrm{m} / z 103.0614 \pm 10 \mathrm{ppm}$

188 was used at a retention time of $4.87 \pm 0.5 \mathrm{~min}$. The limit of quantification (LoQ) was $300 \mathrm{ng} / \mathrm{L}$.

189 Intra- and interday variations of the analytical method $(n=4)$ were 4.6 and $8.5 \%$.

190 


\section{Analysis of tissue samples by SPE and CE-MS}

192 The guanylurea concentration in the tissue of brown trout fry was determined by capillary

193 electrophoresis-mass spectrometry (CE-MS). For sample clean-up and extraction of guanylurea

194 solid-phase extraction (SPE) was used. Fish samples originating from all exposure

195 concentrations were analysed. For each exposure group, tissue samples of three individuals per

196 replicate (nine per treatment) were pooled to reach the required detection limits. For sample

197 preparation, frozen $\left(-20^{\circ} \mathrm{C}\right)$ samples were first homogenised by grinding using a mortar and

198 pestle under liquid nitrogen. A total of $100 \mathrm{mg}$ of the homogenised sample was transferred to an

199 Eppendorf tube and $1.5 \mathrm{~mL}$ water were added, followed by vortexing for $30 \mathrm{~s}$. After

200 centrifugation for $15 \mathrm{~min}$, the supernatant was transferred into an Eppendorf tube and was then

201 ready for SPE extraction. Prior to the extraction, the material was conditioned with $3 \times 3 \mathrm{~mL}$

202 methanol followed by $3 \times 3 \mathrm{~mL}$ of water (LC-MS grade). After equilibrating, $1 \mathrm{~mL}$ sample extract

203 was loaded onto the cartridges. Elution of guanylurea was performed with $1 \mathrm{~mL}$ of

204 methanol/acetonitrile mixture containing $2 \%$ formic acid. The eluate was evaporated to dryness

205 under a gentle stream of nitrogen and the concentrated residue was redissolved in $300 \mu \mathrm{L}$

206

207 methanol. After filtration using a $45 \mu \mathrm{m}$ PTFE filter (pore size $0.45 \mu \mathrm{m}$, Chromafil, Macherey-

208 Nagel, Germany), the samples were analysed by CE-MS. Calibration was performed between 5 and $50 \mu \mathrm{g} / \mathrm{L}$ in fish extract and the recovery was determined to $84 \%$. The intraday variation of

209 the analytical method was $9 \%$. Further details can be found in Supplement.

210

All analyses were performed using an Agilent CE 7100 interfaced to an Agilent 6550 iFunnel QTOF mass spectrometer (Agilent Technologies, Waldbronn, Germany and Santa Clara, CA, USA) using an electrospray ionisation source assisted by the sheath-liquid interface. The CE separations were carried out by means of an uncoated fused-silica capillary (length $80 \mathrm{~cm}$, i.d. 50 $\mu \mathrm{m})$. The background electrolyte was a mixture of $25 \mathrm{mM}$ ammonium acetate and $3 \%$ glacial acetic acid in methanol. Samples were injected hydrodynamically by applying a pressure of 100 mbar for $10 \mathrm{~s}$. The CE capillary was kept at $25^{\circ} \mathrm{C}$ during $\mathrm{CE}$ runs and a voltage of $+30 \mathrm{kV}$ was applied. Details on the CE-MS method are given in Supplement (Paragraph S2).

\section{Histopathological investigations}

219 Samples for histological analyses were fixed in $2 \%$ glutardialdehyde (Merck, Darmstadt, Germany) diluted with a sodium-cacodylate buffer (0.1 M, pH 7.6; AppliChem Darmstadt, Germany). After being washed three times with this buffer, samples were dehydrated in a graded series of ethanol and infiltrated with paraffin wax (Parablast; Leica, Wetzlar, Germany) in a tissue processor (Leica TP 1020). Additionally, the kidney samples were decalcified prior to the infiltration step using a 1:2 mixture of formic acid and $70 \%$ ethanol. After paraffin embedding, samples were cut into $3 \mu \mathrm{m}$ slices using a microtome (Leica SM $2000 \mathrm{R}$ ). One portion of the slices was stained with hematoxilin-eosin (to visualise nuclei, cytoplasm, connective tissue and muscles), the other one was stained with alcian blue-PAS (to visualise mucus and glycogen). The slides were examined using a light microscope (Axioskop 2; Zeiss, Oberkochen, Germany), first in a qualitative manner to obtain a general overview of the tissues and to identify pathologies. In 
230 a second step, the observed pathologies were semi-quantitatively assessed and classified into one 231 of five different categories (1: control, 2: slight reaction, 3: medium reaction, 4: strong reaction,

232 5: destruction) according to the criteria published by Triebskorn et al. (2008). In a further step,

233 all samples were re-analysed once again after being blinded and randomised to avoid observer

234 bias in the final evaluation.

\section{Stress protein analysis}

236 For the determination of the $70 \mathrm{kDa}$ stress protein family (Hsp70) level in the heads of juvenile

237 brown trout (21 per treatment), the samples were homogenised with a mixture of $98 \%$ extraction

238 buffer and $2 \%$ protease inhibitor as described by Dieterich et al. (2015). Subsequently, the total

239 protein content in the samples was quantified according to Bradford (1976). A standardised

240 amount of $40 \mu \mathrm{g}$ total protein per sample was used for the analysis of the Hsp70 level. The

241 proteins were separated according to their weight using minigel SDS-PAGE (sodium dodecyl

242 sulfate polyacrylamide gel electrophoresis) and blotted on a nitrocellulose membrane in a semi-

243 dry chamber. After specific binding of the primary antibody (monoclonal $\alpha-\mathrm{Hsp} 70 \mathrm{IgG}$; Dianova

244 Hamburg, Germany) to the Hsp70 proteins, a secondary antibody (peroxidase-coupled $\alpha$-IgG;

245 Jackson Immunoresearch, West Grove, PA, USA) directed to the first antibody was added.

246 Finally, the membranes were stained with 4-chloro-1-naphthol until the Hsp70 proteins became

247 visibly. The optical volume (=band area $\mathrm{x}$ average grey scale value) of the bands was quantified

248 in relation to an internal standard (brown trout full body homogenate).

249 Lipid peroxide analysis

250 The level of lipid peroxides in the head of the brown trout larvae (30 per treatment) was

251 determined with the FOX (ferrous oxidation xylenol orange)-assay according to a modified

252 version of the protocols from Hermes-Lima et al. (1995) and Monserrat et al. (2003). Basically,

$253 \mathrm{Fe}(+\mathrm{II})$ is oxidised by the lipid peroxides of the sample under acidic conditions, followed by a

254 complexation of the resulting $\mathrm{Fe}(+\mathrm{III})$ with the dye xylenol orange resulting in a colour change.

255 Head samples were homogenised in HPLC-grade methanol (according to a tissue: methanol ratio

256 of 1:7, w.w.) and centrifuged at $4^{\circ} \mathrm{C}$ at $14000 \mathrm{rpm}$ for $5 \mathrm{~min} .50 \mu \mathrm{L}$ of $\mathrm{FeSO}_{4}, \mathrm{H}_{2} \mathrm{SO}_{4}$ and

257 xylenol orange each, $35 \mu \mathrm{L}$ sample supernatant and $15 \mu \mathrm{L}$ bi-destilled water were pipetted in

258 each well, adding up to a total volume of $200 \mu \mathrm{L}$. Each sample was tested in triplicate and,

259 additionally, tested without $\mathrm{FeSO}_{4}$ to account for endogenous iron in the sample. Subsequently,

260 the samples were incubated for $90 \mathrm{~min}$ at room temperature. Then, the absorbance was measured

261 at $570 \mathrm{~nm}$ using an automated microplate reader (Bio-Tek Instruments; Winooski, VT, USA).

262 Finally, $1 \mu \mathrm{L}$ of $1 \mathrm{mM}$ cumene hydroperoxide (CHP) solution was added per well and the

263 samples were incubated for $30 \mathrm{~min}$ at room temperature. Then, the absorbance was measured

264 again and cumene hydroperoxide equivalents (CHPequiv.) were calculated according to the

265 following equation:

266

$$
\text { CHPequiv. }=\frac{A b s_{570} \text { before } C H P}{A b s_{570} \text { after } C H P} * \text { volume }_{C H P} * \frac{\text { total volume }}{\text { sample volume }} * \text { dilution factor }
$$


267 with volume $\mathrm{CHP}=1 \mu \mathrm{L}$; total volume $=200 \mu \mathrm{L}$; sample volume $=25 \mu \mathrm{L}$; dilution factor $=4$.

\section{Analysis of swimming behaviour}

270 The swimming behaviour of the juvenile brown trout was quantitatively analysed using the

271 EthoVision 12 software (Noldus, Wageningen, The Netherlands). Three fish per replicate (nine

272 per treatment) were transferred to cubic aquaria $(17 \mathrm{~cm}$ edge length) containing $1.6 \mathrm{~L}$ of the

273 respective test medium. After acclimation for $2 \mathrm{~min}$, swimming behaviour was recorded for 18

274 min with a digital camera (Basler acA1300-60gm camera, 1.3 MP resolution; Basler,

275 Ahrensburg, Germany) in four aquaria simultaneously. By tracking the centre-point of the fish,

276 the total distance moved and the mean velocity of each individual were analysed. Afterwards,

277 possible identity swaps between the tracked individuals were corrected with the Track Editor of

278 EthoVision.

\section{Statistical analysis}

280 Statistics were conducted with JMP 12 (SAS, Cary, NC, USA). Whenever normal distribution

281 and homoscedasticity were not given, data were transformed. The data of body weight of larval

282 brown trout and the data of the swimming behaviour were transformed with a natural logarithm

283 function. Body length and weight of the juveniles as well as the data of the lipid peroxide

284 analysis of the larvae were transformed with the function $\mathrm{x}^{-0.5}$. Mortality and time to hatch were

285 analysed with COX-regression. The histopathological data were checked for significance with

286 the likelihood-ratio- $\chi^{2}$-test. For the analysis of the lipid peroxide level of the larvae, a Welch

287 ANOVA was performed, since the data could not be transformed to reach homoscedasticity. A

288 nested ANOVA was conducted for all other endpoints using the replicate as a nesting factor. The

$289 \alpha$-level was set to 0.05 , but was adjusted in case of multiple testing according to sequential

290 Bonferroni correction. Comparisons with the hatchery controls were solely conducted

291 qualitatively. The statistical tests used and the corresponding p-values are shown in the Results

292 section; further information (e.g. degrees of freedom and F-values) is given in the Supplement

293 (Paragraph S5).

294 Animal welfare

295 All experiments were approved by the animal welfare committee of the Regional Council of

296 Tübingen, Germany (authorisation ZO 2/16).

297 Credibility of data

298 The details about the fulfilment of the criteria for reporting and evaluation ecotoxicity data

299 (CRED) according to Moermond et al. (2016) are provided in the supplement (Paragraph S6). 
300

301

302

303

304

305

306

307

308

309

310

311

312

\section{Mortality and growth metrics}

314 The mortality varied between 2.2 and $6.7 \%$ in the experiment with the larval brown trout (Table

315 1) and between 0 and $3.3 \%$ in the experiment with juvenile brown trout (Table 2), so guanylurea

316 did not show any signs of a lethal effect (COX-regression: larvae: $p=0.2001$; juveniles:

$317 \mathrm{p}=0.4253)$ in the tested concentration range. Also, body weight, length and condition factor of

318 both life stages of brown trout were not influenced by guanylurea (Table 1 and 2) (nested

319

320

321

322

323

324

325

326

327

328

329

330

331

332

333

334 ANOVA: larvae: $\mathrm{p}=0.8919$ (weight); $\mathrm{p}=0.0589$ (length); $\mathrm{p}=0.0587$ (condition factor); juveniles: $\mathrm{p}=0.6383$ (weight); $\mathrm{p}=0.8157$ (length); $\mathrm{p}=0.7942$ (condition factor)).

\section{Developmental parameters}

The investigations of heart rate and time to hatch did not reveal any effects of guanylurea in larval brown trout (Table 1) (heart rate: nested ANOVA: $\mathrm{p}=0.9090$; time to hatch: COXregression: $\mathrm{p}=1)$. Moreover, the hatching success in all exposure groups was $100 \%$.

\section{Biochemical markers}

The analysis of lipid peroxides in larval brown trout did not reveal any differences between the exposure groups (Table 1) (Welch-ANOVA: $\mathrm{p}=0.2333$ ). Also, the stress protein level in juvenile brown trout was not influenced by guanylurea (Table 2) (nested ANOVA: $\mathrm{p}=0.3235$ ).

\section{Swimming behaviour}

The total distance moved and mean velocity of juvenile brown trout exposed to $10 \mu \mathrm{g} / \mathrm{L}$ guanylurea were slightly, but not significantly enhanced compared to the control (Table 2). This was not observed after exposure to the higher test concentrations (nested ANOVA: dist. moved: $\mathrm{p}=0.1676$; mean velocity: $\mathrm{p}=0.1676$ ). 


\section{Histopathology}

\section{Liver}

337 The liver tissue of larval brown trout did not show any severe damage or pathological alterations

338

339

340

341

342

343

344

345

346

347

348

349

350

351

352

353

354

355

356

357

358

359

360

361

362

363

364

365

366

367

368

369

370

371 and was classified into the categories 1,2 or 3 . For the liver samples of juvenile brown trout, categories 1 to 4 were allocated to the sections. In both life stages, one portion of the liver samples showed large cells with a bright cytoplasm (Fig. 1A, 1C) containing high amounts of glycogen (Fig. 1B). The other portion of the samples revealed small and darker hepatocytes (Fig. 1D) and a low glycogen amount (Fig. 1E). The glycogen amount was generally lower in the livers of juveniles compared to larval brown trout. Moreover, large inflammatory sites (Fig. 1F), which occurred in some livers of juvenile brown trout exposed to guanylurea, resulted in a classification into category 4 . Further details of the qualitative tissue analyses for each individual are given in the Supplement (Paragraph S4). The semi-quantitative histopathological assessment of the liver did not show any significant effects of guanylurea in larval or juvenile brown trout (Likelihood-ratio- $\chi^{2}$-test: larvae: $\mathrm{p}=0.2865$; juveniles: $\mathrm{p}=0.5224$ ) (Fig. 2 ). In the hatchery control, the livers contained more glycogen compared to the juvenile brown trout exposed in laboratory, but the prevalence of inflammatory sites resulted in a classification of the respective samples into categories 3 and 4 (Fig. 2).

\section{Kidney}

The kidney tissue of juvenile brown trout was classified into the categories 1 to 4 . Symptoms were the enlargement of vesicles and the accumulation of hyaline droplets (Fig. 1H) in anterior parts of the proximal tubules and the occurrence of vacuoles (Fig. 1I) in anterior and posterior parts of the proximal tubules. In few kidney sections, the hematopoietic tissue was partially degenerated and the spaces between the glomeruli and the Bowman's capsules were enlarged. The semi-quantitative assessment revealed that these symptoms were prevalent in all treatments and that there was no observable difference between the exposure groups with guanylurea and the control (Likelihood-ratio- $\chi^{2}$-test: $p=0.6668$; Fig. 2). In the hatchery control (Fig. $1 G$ ), however, symptoms as described above did not occur except for one single animal. Further details of the qualitative tissue analyses for each individual are given in the Supplement (Paragraph S4).

\section{Discussion}

In the present study, we investigated the effects of guanylurea, the major transformation product of metformin, in brown trout. Generally, it is assumed that most metabolites or transformation products show the same behaviour in the environment as their parent compounds (EMA 2006) and are equally or less toxic than these (Escher \& Fenner 2011; Kümmerer 2009). With respect to guanylurea, however, there is a lack of ecotoxicological data, and it is not known whether this transformation product resembles metformin in its (ecotoxic) effects. Usually, a similar chemical structure of transformation product and parent compound indicates a similar environmental 
372 behaviour. The general chemical properties of guanylurea are similar to those of the parent

373 compound: both substances are very polar and positively charged at $\mathrm{pH}$ values of natural waters

374 (Scheurer et al. 2012; Scheurer et al. 2009). It has been shown that metformin can be taken up by

375 fish to some extend leading to tissue concentrations of about $55 \mathrm{ng} / \mathrm{g}$ in brown trout larvae

376 exposed to $1000 \mu \mathrm{g} / \mathrm{L}$ metformin (Jacob et al. 2018; Ussery 2018). The mean guanylurea

377 concentration in the tissue of larval brown trout exposed to $1000 \mu \mathrm{g} / \mathrm{L}$ was about $11 \mathrm{ng} / \mathrm{g}$, which

378 is a factor of 5 lower compared to metformin. These low internal concentrations of metformin

379 and its transformation product in fish might be related to the high polarity $(\log \mathrm{D}=-3.85$ for

380 guanylurea and -5.62 for metformin; calculation according to chemicalize.com) and charge

381 (single for guanylurea and double for metformin) of these compounds.

382

383

384

385

386

387

388

389

390

391

392

393

394

395

396

397

398

399

400

401

402

403

404

405

406

407

408

409

410

The present study demonstrated that guanylurea did not lead to any lethal or embryotoxic effects in brown trout. Mortality and developmental parameters, like heart rate, hatching success and time to hatch were not influenced by the transformation product of metformin. Also, Ussery et al. (2019) showed that guanylurea did not affect hatching success or time to hatch in Japanese medaka exposed for 28 days in an early life stage test at concentrations of $1-100 \mathrm{ng} / \mathrm{L}$ and for 165 days in a full life cycle test to $1 \mathrm{ng} / \mathrm{L}$ and $7.5 \mu \mathrm{g} / \mathrm{L}$ guanylurea. Investigations of the parent compound metformin revealed comparable results (Jacob et al. 2018; Ussery et al. 2019) neither study showed a negative impact of the pharmaceutical on survival or development up to the highest concentrations applied.

The length and weight of brown trout was not affected by guanylurea, neither in larvae nor in juveniles. When interpreting these results, one has to keep in mind that the brown trout were fed at maintenance and not ad libitum. This feeding regime was chosen due to the semi-static test design, since it is necessary to provide clean water with high oxygen content for brown trout. In contrast, Ussery et al. (2019) showed the weight and length of larval medaka to be decreased by guanylurea, but it was not significantly reduced in adult medaka exposed in a full life-cycle test. Guanylurea had no influence on the condition factor of the two life stages of brown trout; this was also observed by Ussery et al. (2019) for adult medaka. Metformin, the parent compound of guanylurea, clearly reduced the growth of fish. This was shown for early life stages of Japanese medaka (Ussery et al. 2018), but also for brown trout (Jacob et al. 2018) and adult male fathead minnow in a full life cycle test (Niemuth \& Klaper 2015). This metformin-induced effect might be explained by the appetite reducing capacity of metformin which also explains its use as a weight loss drug (Malin \& Kashyap 2014). Guanylurea, in contrast, does not seem to show this activity in brown trout.

The biochemical analyses of lipid peroxides and stress proteins did not reveal any influences of guanylurea on these stress parameters in larval and juvenile brown trout. Likewise, in big ramshorn snails (Planorbarius corneus) exposed to $0.1-100 \mathrm{mg} / \mathrm{L}$ guanylurea for 21 days, lipid peroxides and stress proteins were not changed by guanylurea (Jacob et al. 2019). Thus, one explanation could be that guanylurea does not induce proteotoxic or oxidative stress at all. 
411 However, it could also be regarded possible that the peroxidation of lipids was prevented by 412 increased activity of glutathione peroxidase, superoxide dismutase or catalase, which would lead 413 to a neutralization of ROS. Therefore, additional analysis of these antioxidant enzymes would be 414 of advantage to gain more detailed insights into oxidative stress exerted in fish. This, however, 415 was not possible in the present study due to restrictions with respect to tissue availability. Further 416 information concerning the effects of guanylurea on stress proteins and lipid peroxides does - to 417 the best of our knowledge- not exist in the literature. The structurally similar compound 418 guanidine serves as a scavenger for ROS, so it contributes to reducing oxidative stress (Yildiz et 419 al. 1998). The parent compound metformin was also shown to reduce the production of ROS; its 420 anti-oxidative effect is known for type 2 diabetes patients who are prone to oxidative stress 421 (Bonnefont-Rousselot et al. 2003; Bułdak et al. 2014; Dehkordi et al. 2018). However, in a study 422 with Japanese medaka, metformin increased the ROS level in male fish and the catalase activity in female fish, but it also reduced the glutathione level in male fish (Lee et al. 2019). Phenformin, an antidiabetic drug related to metformin, was shown to reduce ROS generation in the serum of rats, whereas it increased the ROS production in the brain (Anisimov et al. 2005). The same drug had no effect on the Hsp70 levels in hippocampal neurons (Lee et al. 2002). In contrast, the expression of stress protein Hsp70 was shown to be reduced by metformin in the pancreas of rats exposed to high free fatty acid levels (Piro et al. 2012). Despite all this information on chemically similar compounds, there is, currently, no indication that the transformation product guanylurea may exert or reduce oxidative or proteotoxic effects.

The swimming behaviour of juvenile brown trout also did not provide any evidence for a possible harmfulness of guanylurea. The high variation in the activity of brown trout exposed to $10 \mu \mathrm{g} / \mathrm{L}$ guanylurea was caused by exceptionally high swimming activity (total distance moved $>2000 \mathrm{~cm}$ ) of three out of nine individuals in this exposure group. Unfortunately, a comparison with literature data is not possible because studies dealing with the effects of guanylurea on behaviour are lacking. As shown in a previous study, neither the parent compound metformin changed the movement activity of brown trout larvae (Jacob et al. 2018) or the locomotor activity of zebrafish (Godoy et al. 2018). However, MacLaren et al. (2018) showed that metformin can influence the aggressive behaviour of Siamese fighting fish (Betta splendens). Generally, endpoints of locomotor and movement activity seem to be suitable parameters for the assessment of neuroactive drugs like antidepressants (Brodin et al. 2014) as, e.g. citalopram enhanced the swimming activity of three-spine strickleback (Kellner et al. 2016). Since

443 physiological stress effects were lacking in our experiments with guanylurea, it seems plausible 444 that no behavioural disruption occurred.

445 The histopathological examinations did not reveal any guanylurea-induced changes in liver and 446 kidney of brown trout. With respect to the two investigated life stages, the livers of larval brown 447 trout were generally in a better condition than the livers of the juveniles. Since the test organisms 448 449 in the lab were fed at maintenance but not ad libitum as the latter is the case in breeding farms such feeding regime could result in a lower hepatic glycogen amount, particularly for the larger 
450 juveniles. Symptoms like hyaline droplets and vacuoles in the proximal tubules of the kidney of 451 the juveniles might be related to the altered water parameters, e.g. conductivity and $\mathrm{pH}$,

452 compared to the situation in the trout breeding farm. Such symptoms have also been observed in 453 another study with brown trout in a laboratory experiment (Schwarz et al. 2017). The absence of 454 reactions in the kidney of the hatchery controls support this assumption. An increase in the 455 hepatic glycogen amount, as it was the case for brown trout exposed to metformin (Jacob et al. 456 2018) indicating the therapeutical effect of the drug on glycogen depletion, could not be 457 observed in the experiments with guanylurea.

458

459

460

461

462

463

464

465

466

467

468

469

470

471

472

473

474

475

476

477

478

479

480

481

482

483

484

485

486

487

488

489
Overall, none of the investigated endpoints in the present study revealed any effect of guanylurea on the development or health of brown trout. However, Ussery (2018) indicated that the transformation product of metformin can influence the hormone system, since the estradiol production in the liver of adult, male Japanese medaka exposed in a full life cycle test to 7.5 $\mu \mathrm{g} / \mathrm{L}$ guanylurea was increased. This is of particular importance since the parent compound metformin was shown to exert endocrine effects in fathead minnow (Pimephales promelas) with an upregulation of vitellogenin mRNA in juveniles (Crago et al. 2016) and adult males (Niemuth et al. 2015), the occurrence of intersex in adult males and a reduced fecundity of mating pairs (Niemuth \& Klaper 2015). However, vitellogenin production in the liver was not induced by guanylurea in Japanese medaka (Ussery 2018). Therefore, future studies should focus more explicitly on this hormone-changing aspect of guanylurea and the mode of action behind it.

In general, transformation products play a minor role in the regulation of pharmaceuticals. In the European Medicines Agency (EMA) guideline on the environmental risk assessment of medical products for human use, tests according to the OECD 308 on transformation of organic chemicals in water/sediment systems are requested for the base data set of each pharmaceutical which is provided in phase II, tier A of the environmental risk assessment (EMA 2006). These tests serve for the identification and quantification of transformation products that are formed at a percentage of $\geq 10 \%$ of the applied dose of the parent compound (OECD 2002). Berkner and Thierbach (2014) examined the OECD 308 tests of dossiers for marketing authorisation applications of pharmaceuticals and found $70 \%$ of the tests to show a formation of at least one transformation product, but only $26 \%$ of the studies to identify this product. These results reveal a significant data gap for transformation products of pharmaceuticals formed in the environment. To date, in the new draft for the guideline on the environmental risk assessment of pharmaceuticals of the EMA, the identification of transformation products according to the OECD 308 is supposed to no longer being part of the base data set of phase II, tier A (EMA 2018). Consequently, the environmental risk assessment of pharmaceuticals will stay 'blind' for the formation and action of transformation products. In addition, an evaluation of the ecotoxic effects of the transformation products is not mandatory for an environmental risk assessment of pharmaceuticals. This, however, would be of particular importance for transformation products which are very persistent or occur at higher environmental concentrations than its parent compound as it is the case for guanylurea.

Peer) reviewing PDF | (2019:04:37127:1:1:NEW 2 Jun 2019) 


\section{Conclusion}

491 Our study showed that guanylurea neither led to lethal, embryotoxic nor behavioural effects in

492 brown trout at the tested concentrations. Also, length, weight, biochemical markers (stress

493 proteins and lipid peroxides) and the tissue integrity of the main metabolic organs (liver and

494 kidney) were not influenced by the transformation product of metformin. Internal concentrations

495 were very low. Investigations of ecotoxic effects of transformation products are scarce in general

496 and this also applies to guanylurea. Thus, we consider our present study as a rather elaborate

497 starting point, at least for a risk assessment of fish toxicity, even though we admit that a final

498 evaluation of the ecotoxic potential of guanylurea has not been completed, particular in view of

499 its endocrine potential. Nevertheless, we appeal to authorities to go ahead and implement the

500 present data into the environmental risk assessment of the parent compound metformin.

\section{Acknowledgements}

502 This study is part of the project Effect-Net (Effect Network in Water Research) which is part of

503 the Wassernetzwerk Baden-Württemberg and funded by the Ministry for Science, Research and

504 Arts of Baden-Württemberg. Particular thanks go to Thomas Braunbeck, Heidelberg University,

505 for the coordination of this project. We are grateful to Melanie Biecker and Eileen Pfitzer for the

506 analysis of biochemical markers which were conducted in context of their bachelor theses.

507 Furthermore, we thank Andreas Dieterich, Birgit Dittrich, Stefanie Krais, Lone Kundy,

508 Katharina Peschke, Judith Rüschhoff, Hannah Schmieg, Simon Schwarz, Sabrina Wilhelm and

509 Michael Ziegler for technical assistance and help in the lab.

\section{References}

512 Anisimov VN, Ukraintseva SV, Anikin IV, Popovich IG, Zabezhinski MA, Bertsein LM, Arutjunyan AV, Ingram

DK, Lane MA, and Roth GS. 2005. Effects of phentermine and phenformin on biomarkers of aging in rats. Gerontology 51:19-28. https://doi.org/10.1159/000081430

Anurag P, and Anuradha C. 2002. Metformin improves lipid metabolism and attenuates lipid peroxidation in high fructose-fed rats. Diabetes Obes Metab 4:36-42. https://doi.org/10.1046/j.1463-1326.2002.00178.x

Berkner S, and Thierbach C. 2014. Biodegradability and transformation of human pharmaceutical active ingredients in environmentally relevant test systems. Environmental Science Pollution Research 21:9461-9467. https://doi.org/10.1007/s11356-013-1868-6

Bernet D, Schmidt H, Meier W, Burkhardt-Holm P, and Wahli T. 1999. Histopathology in fish: proposal for a protocol to assess aquatic pollution. Journal of Fish Diseases 22:25-34. http://dx.doi.org/10.1046/j.1365$\underline{2761.1999 .00134 . \mathrm{X}}$

523 Betteridge DJ. 2000. What is oxidative stress? Metabolism 49:3-8. https://doi.org/10.1016/s0026-0495(00)80077-3 
527

528

529

530

531

532

533

534

535

536

537

538

539

540

541

542

543

544

545

546

547

548

549

550

551

552

553

554

555

556

557

558

559

560

561

562

563

564

565

566

Bradford MM. 1976. A rapid and sensitive method for the quantitation of microgram quantities of protein utilizing the principle of protein-dye binding. Analytical Biochemistry 72:248-254. https://dx.doi.org/10.1016/0003$\underline{2697(76) 90527-3}$

Brodin T, Piovano S, Fick J, Klaminder J, Heynen M, and Jonsson M. 2014. Ecological effects of pharmaceuticals in aquatic systems - impacts through behavioural alterations. Philosophical Transactions of the Royal Society B: Biological Sciences 369:20130580. https://doi.org/10.1098/rstb.2013.0580

Bułdak Ł, Łabuzek K, Bułdak RJ, Kozłowski M, Machnik G, Liber S, Suchy D, Duława-Bułdak A, and Okopień B. 2014. Metformin affects macrophages' phenotype and improves the activity of glutathione peroxidase, superoxide dismutase, catalase and decreases malondialdehyde concentration in a partially AMPKindependent manner in LPS-stimulated human monocytes/macrophages. Pharmacological Reports 66:418429. https://doi.org/10.1016/j.pharep.2013.11.008

Caldwell DJ, D'Aco V, Davidson T, Kappler K, Murray-Smith RJ, Owen SF, Robinson PF, Simon-Hettich B, Straub JO, and Tell J. 2019. Environmental risk assessment of metformin and its transformation product guanylurea: II. Occurrence in surface waters of Europe and the United States and derivation of predicted no-effect concentrations. Chemosphere 216:855-865. https://doi.org/10.1016/j.chemosphere.2018.10.038

Celiz MD, Tso J, and Aga DS. 2009. Pharmaceutical metabolites in the environment: analytical challenges and ecological risks. Environmental Toxicology and Chemistry 28:2473-2484. https://doi.org/10.1897/09-173.1

ChemIDplus. https://chem.nlm.nih.gov/chemidplus/name/guanylurea (accessed 16.08.2018.

Chen JJ, and Yu BP. 1994. Alterations in mitochondrial membrane fluidity by lipid peroxidation products. Free Radical Biology and Medicine 17:411-418. https://doi.org/10.1016/0891-5849(94)90167-8

Crago J, Bui C, Grewal S, and Schlenk D. 2016. Age-dependent effects in fathead minnows from the anti-diabetic drug metformin. General and Comparative Endocrinology 232:185-190.

http://dx.doi.org/10.1016/j.ygcen.2015.12.030

Dai J, Liu M, Ai Q, Lin L, Wu K, Deng X, Jing Y, Jia M, Wan J, and Zhang L. 2014. Involvement of catalase in the protective benefits of metformin in mice with oxidative liver injury. Chemico-Biological Interactions 216:34-42. https://doi.org/10.1016/j.cbi.2014.03.013

Dehkordi AH, Abbaszadeh A, Mir S, and Hasanvand A. 2018. Metformin and its anti-inflammatory and antioxidative effects; new concepts. Journal of Renal Injury Prevention 8:54-61.

Dieterich A, Troschinski S, Schwarz S, Di Lellis MA, Henneberg A, Fischbach U, Ludwig M, Gärtner U, Triebskorn R, and Köhler H-R. 2015. Hsp70 and lipid peroxide levels following heat stress in Xeropicta derbentina (Krynicki 1836) (Gastropoda, Pulmonata) with regard to different colour morphs. Cell Stress \& Chaperones 20:159-168. http://dx.doi.org/10.1007/s12192-014-0534-3

EMA. 2006. Guideline on the environmental risk assessment of medicinal products for human use. London: European Medicines Agency, Committee for Medicinal Products for Human Use.

EMA. 2018. Draft - Guidline on the environmental risk assessment of medicinal products for human use. London: European Medicines Agency, Committee for Medicinal Products for Human Use.

Escher BI, and Fenner K. 2011. Recent advances in environmental risk assessment of transformation products. Environmental Science and Technology 45:3835-3847. https://doi.org/10.1021/es1030799

EU. 2006. Council Directive 2006/88/EC on animal health requirements for aquaculture animals and products thereof, and on the prevention and control of certain diseases in aquatic animals. Available at https://eur-

Peer) reviewing PDF | (2019:04:37127:1:1:NEW 2 Jun 2019) 
567

568

569

570

571

572

573

574

575

576

577

578

579

580

581

582

583

584

585

586

587

588

589

590

591

592

593

594

595

596

597

598

599

600

601

602

603

604

605

lex.europa.eu/LexUriServ/LexUriServ.do? uri=OJ:L:2006:328:0014:0056:en:PDF\%20 (accessed 19.09.2018.

Godoy AA, Domingues I, Nogueira AJA, and Kummrow F. 2018. Ecotoxicological effects, water quality standards and risk assessment for the anti-diabetic metformin. Environmental Pollution. https://doi.org/10.1016/j.envpol.2018.09.031

Helbling DE, Hollender J, Kohler H-PE, Singer H, and Fenner K. 2010. High-throughput identification of microbial transformation products of organic micropollutants. Environmental Science \& Technology 44:6621-6627. https://doi.org/10.1021/es100970m

Hermes-Lima M, Willmore WG, and Storey KB. 1995. Quantification of lipid peroxidation in tissue extracts based on Fe (III) xylenol orange complex formation. Free Radical Biology and Medicine 19:271-280. https://doi.org/10.1016/0891-5849(95)00020-x

Jacob S, Dötsch A, Knoll S, Köhler H-R, Rogall E, Stoll D, Tisler S, Huhn C, Schwartz T, and Zwiener C. 2018. Does the antidiabetic drug metformin affect embryo development and the health of brown trout (Salmo trutta f. fario)? Environ Sci Eur 30:48. https://doi.org/10.1186/s12302-018-0179-4

Jacob S, Köhler HR, Tisler S, Zwiener C, and Triebskorn R. 2019. Impact of the antidiabetic drug metformin and its transformation product guanylurea on the health of the big ramshorn snail (Planorbarius corneus). Frontiers in Environmental Science 7:45. https://doi.org/10.3389/fenvs.2019.00045

Johnson LL, Stehr CM, Olson OP, Myers MS, Pierce SM, Wigren CA, McCain BB, and Varanasi U. 1993. Chemical contaminants and hepatic lesions in winter flounder (Pleuronectes americanus) from the Northeast Coast of the United States. Environmental Science \& Technology 27:2759-2771. http://dx.doi.org/10.1021/Es00049a015

Kellner M, Porseryd T, Hallgren S, Porsch-Hällström I, Hansen SH, and Olsén KH. 2016. Waterborne citalopram has anxiolytic effects and increases locomotor activity in the three-spine stickleback (Gasterosteus aculeatus). Aquatic Toxicology 173:19-28. https://doi.org/10.1016/j.aquatox.2015.12.026

Killeen J, McLay H, and Johnston I. 1999. Development in Salmo trutta at different temperatures, with a quantitative scoring method for intraspecific comparisons. Journal of Fish Biology 55:382-404. http://dx.doi.org/10.1006/jfbi.1999.1004

Kümmerer K. 2009. The presence of pharmaceuticals in the environment due to human use-present knowledge and future challenges. Journal of Environmental Management 90:2354-2366. https://doi.org/10.1016/j.jenvman.2009.01.023

Lee J, Chan SL, Lu C, Lane MA, and Mattson MP. 2002. Phenformin suppresses calcium responses to glutamate and protects hippocampal neurons against excitotoxicity. Experimental Neurology 175:161-167. https://doi.org/10.1006/exnr.2002.7864

Lee JW, Shin Y-J, Kim H, Kim H, Kim J, Min S-A, Kim P, Do Yu S, and Park KJJohm. 2019. Metformin-induced endocrine disruption and oxidative stress of Oryzias latipes on two-generational condition. 367:171-181.

MacLaren RD, Wisniewski K, and MacLaren CJPo. 2018. Environmental concentrations of metformin exposure affect aggressive behavior in the Siamese fighting fish, Betta splendens. 13:e0197259.

Malin SK, and Kashyap SR. 2014. Effects of metformin on weight loss: potential mechanisms. Current Opinion in Endocrinology \& Diabetes 21:323-329. http://dx.doi.org/10.1097/MED.0000000000000095

PeerJ reviewing PDF | (2019:04:37127:1:1:NEW 2 Jun 2019) 
606

607

608

609

610

611

612

613

614

615

616

617

618

619

620

621

622

623

624

625

626

627

628

629

630

631

632

633

634

635

636

637

638

639

640

641

642

643

644

645

Margulis B, Antropova O, and Kharazova A. 1989. $70 \mathrm{kDa}$ heat shock proteins from mollusc and human cells have common structural and functional domains. Comparative biochemistry and physiology B, Comparative biochemistry 94:621-623. https://doi.org/10.1016/0305-0491(89)90138-7

Markiewicz M, Jungnickel C, Stolte S, Białk-Bielińska A, Kumirska J, and Mrozik W. 2017. Ultimate biodegradability and ecotoxicity of orally administered antidiabetic drugs. Journal of Hazardous Materials 333:154-161. https://doi.org/10.1016/j.jhazmat.2017.03.030

Moermond CT, Kase R, Korkaric M, and Ågerstrand M. 2016. CRED: Criteria for reporting and evaluating ecotoxicity data. Environmental Toxicology and Chemistry 35:1297-1309. http://dx.doi.org/10.1002/etc.3259

Monserrat JM, Geracitano L, Pinho GLL, Vinagre T, Faleiros M, Alciati JC, and Bianchini A. 2003. Determination of lipid peroxides in invertebrates tissues using the Fe (III) xylenol orange complex formation. Archives of Environmental Contamination and Toxicology 45:177-183. https://doi.org/10.1007/s00244-003-0073-x

Niemuth NJ, Jordan R, Crago J, Blanksma C, Johnson R, and Klaper RD. 2015. Metformin exposure at environmentally relevant concentrations causes potential endocrine disruption in adult male fish. Environmental Toxicology and Chemistry 34:291-296. http://dx.doi.org/10.1002/etc.2793

Niemuth NJ, and Klaper RD. 2015. Emerging wastewater contaminant metformin causes intersex and reduced fecundity in fish. Chemosphere 135:38-45. https://dx.doi.org/10.1016/j.chemosphere.2015.03.060

OECD. 2002. OECD Guideline for the testing of chemicals (308) Aerobic and Anaerobic Transformation in Aquatic Sediment Systems. Available at https://www.oecd-ilibrary.org/environment/test-no-308-aerobic-andanaerobic-transformation-in-aquatic-sediment-systems 9789264070523-en (accessed 08.02.2019.

Piro S, Rabuazzo A, Renis M, and Purrello F. 2012. Effects of metformin on oxidative stress, adenine nucleotides balance, and glucose-induced insulin release impaired by chronic free fatty acids exposure in rat pancreatic islets. Journal of Endocrinological Investigation 35:504-510.

Riegraf C, Fenner K, Werner I, and Kase R. 2017. Grenzwerte für Transformationsprodukte. Aqua \& Gas 2:46-56.

Scheurer M, Michel A, Brauch H-J, Ruck W, and Sacher F. 2012. Occurrence and fate of the antidiabetic drug metformin and its metabolite guanylurea in the environment and during drinking water treatment. Water Research 46:4790-4802. https://dx.doi.org/10.1016/j.watres.2012.06.019

Scheurer M, Sacher F, and Brauch H-J. 2009. Occurrence of the antidiabetic drug metformin in sewage and surface waters in Germany. Journal of Environmental Monitoring 11:1608-1613. http://dx.doi.org/10.1039/b909311g

Schlüter-Vorberg L, Prasse C, Ternes TA, Mückter H, and Coors A. 2015. Toxification by transformation in conventional and advanced wastewater treatment: the antiviral drug acyclovir. Environmental Science \& Technology Letters 2:342-346. https://doi.org/10.1021/acs.estlett.5b00291

Schwaiger J, Bucher F, Ferling H, Kalbfus W, and Negele R-D. 1992. A prolonged toxicity study on the effects of sublethal concentrations of bis (tri-n-butyltin) oxide (TBTO): histopathological and histochemical findings in rainbow trout (Oncorhynchus mykiss). Aquatic Toxicology 23:31-48. http://dx.doi.org/10.1016/0166445x(92)90010-K

Schwarz S, Schmieg H, Scheurer M, Köhler H-R, and Triebskorn R. 2017. Impact of the NSAID diclofenac on survival, development, behaviour and health of embryonic and juvenile stages of brown trout, Salmo trutta f. fario. Science of the Total Environment 607:1026-1036. https://doi.org/10.1016/j.scitotenv.2017.07.042

Peer) reviewing PDF | (2019:04:37127:1:1:NEW 2 Jun 2019) 
646 Scott GR, and Sloman KA. 2004. The effects of environmental pollutants on complex fish behaviour: integrating

647

648 behavioural and physiological indicators of toxicity. Aquatic Toxicology 68:369-392. https://doi.org/10.1016/j.aquatox.2004.03.016

Tisler S, and Zwiener C. 2018. Formation and occurrence of transformation products of metformin in wastewater and surface water. Science of the Total Environment 628:1121-1129.

651 http://dx.doi.org/10.1016/j.scitotenv.2018.02.105

652

653

654

655

656

657

658

659

660

Ussery E. 2018. The ecotoxicological effects of metformin and its metabolite, guanylurea, on Japanese medaka (Oryzias latipes) dissertation. University of Ontario.

661

662

663

Ussery E, Bridges KN, Pandelides Z, Kirkwood AE, Bonetta D, Venables BJ, Guchardi J, and Holdway D. 2018. Effects of environmentally relevant metformin exposure on Japanese medaka (Oryzias latipes). Aquatic Toxicology 205:58-65. https://doi.org/10.1016/j.aquatox.2018.10.003

664

665

666

667

668

669

Valavanidis A, Vlahogianni T, Dassenakis M, and Scoullos M. 2006. Molecular biomarkers of oxidative stress in aquatic organisms in relation to toxic environmental pollutants. Ecotoxicology and Environmental Safety 64:178-189. https://doi.org/10.1016/j.ecoenv.2005.03.013

670

671

Yildiz G, Demiryürek AT, Sahin-Erdemli I, and Kanzik I. 1998. Comparison of antioxidant activities of aminoguanidine, methylguanidine and guanidine by luminol-enhanced chemiluminescence. British Journal of Pharmacology 124:905-910. https://doi.org/10.1038/sj.bjp.0701924

673 


\section{Figure 1}

Representative sections of liver and kidney of brown trout

Control status of liver of A) juvenile and C) larval brown trout with large hepatocytes with bright cytoplasm and B) high glycogen amounts; reaction status of liver with D) small hepatocytes with E) reduced glycogen amounts and F) inflammatory sites; control status of kidney showing G) proximal tubules in compact hematopoietic tissue; reaction status of kidney showing $\mathrm{H}$ ) hyaline droplets and I) vacuoles in the proximal tubules; B) \& E): alcian blue-PAS staining; all other sections: haematoxylin-eosin staining; C): liver section of larval brown trout; all other sections: juvenile brown trout.
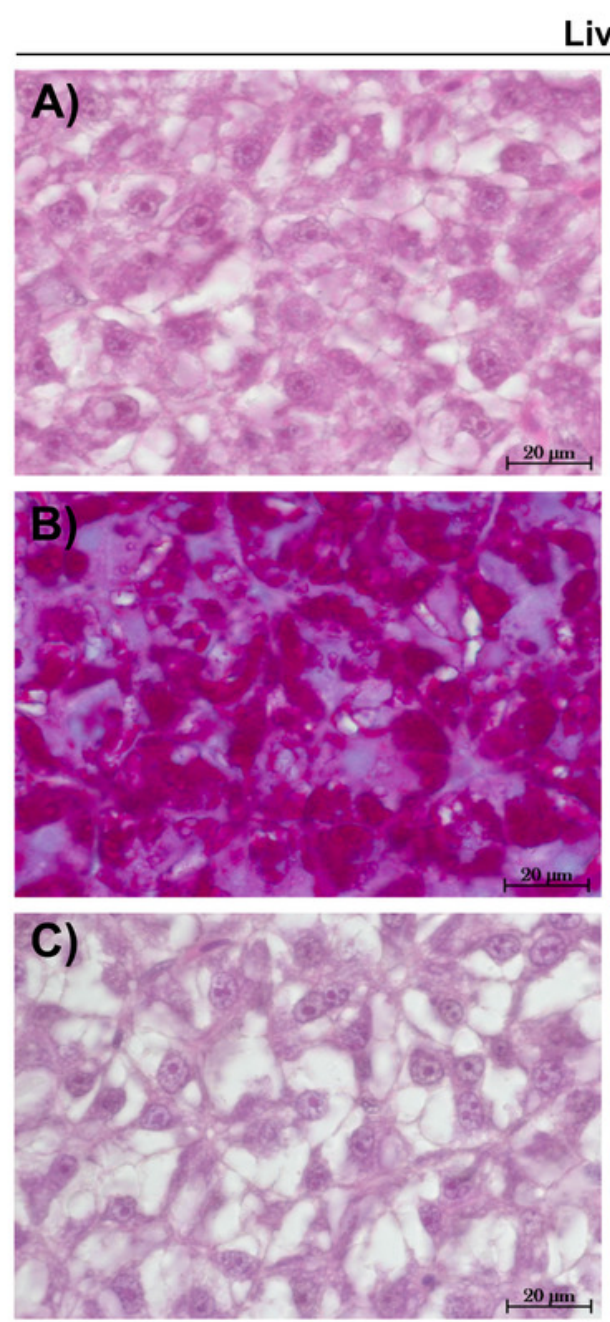

Liver
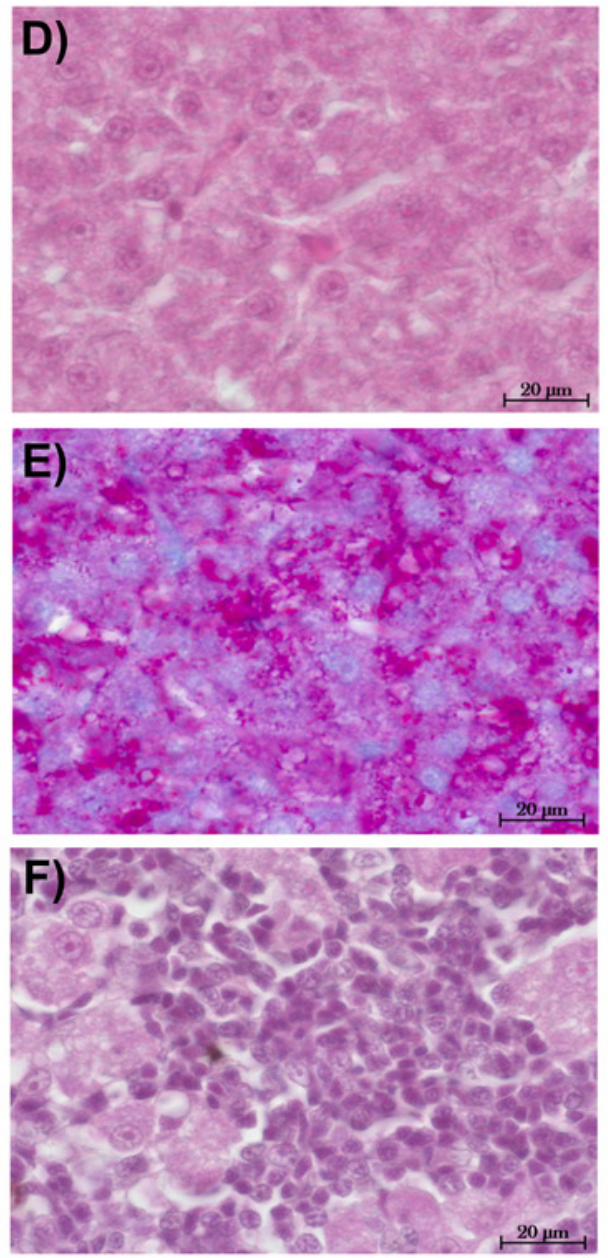

Kidney
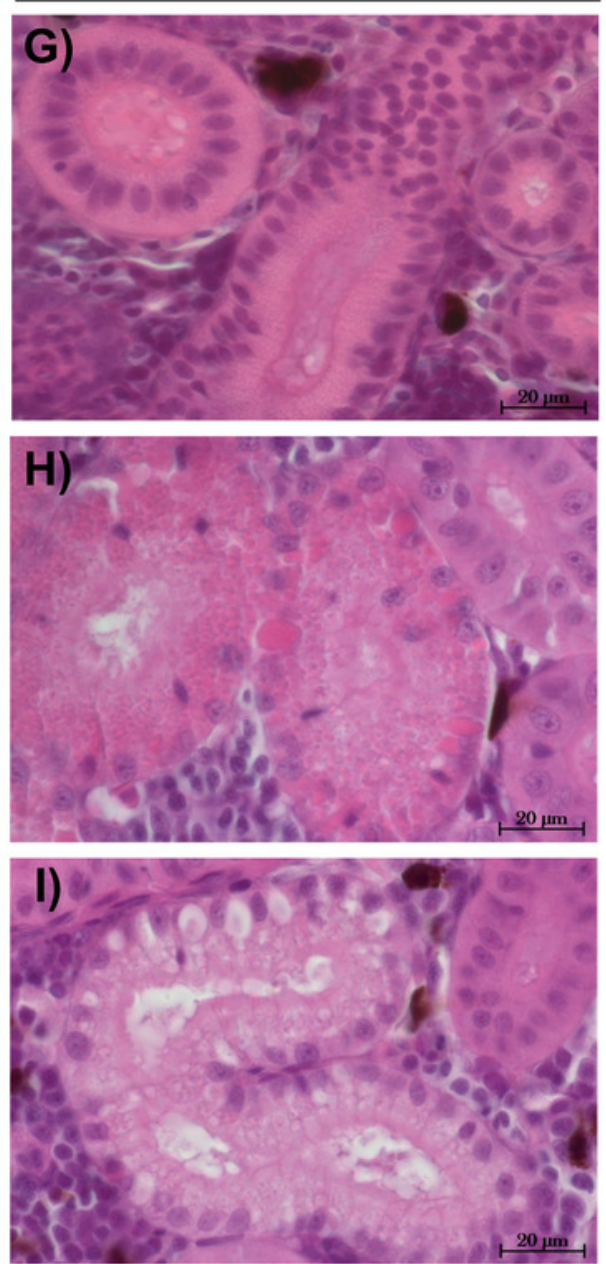


\section{Figure 2}

Semi-quantitative assessment of histopathological symptoms in the liver of larval brown trout and in the liver and kidney of juvenile brown trout exposed to guanylurea.

Samples were classified in categories 1 to 4; category 5 was not allocated to any of the samples. The number $\mathrm{n}$ of examined individuals is given at the base of each bar. Statistical comparisons revealed that guanylurea did not significantly affect the integrity of the investigated tissues. Hatchery controls (HC) were excluded from statistical comparison.
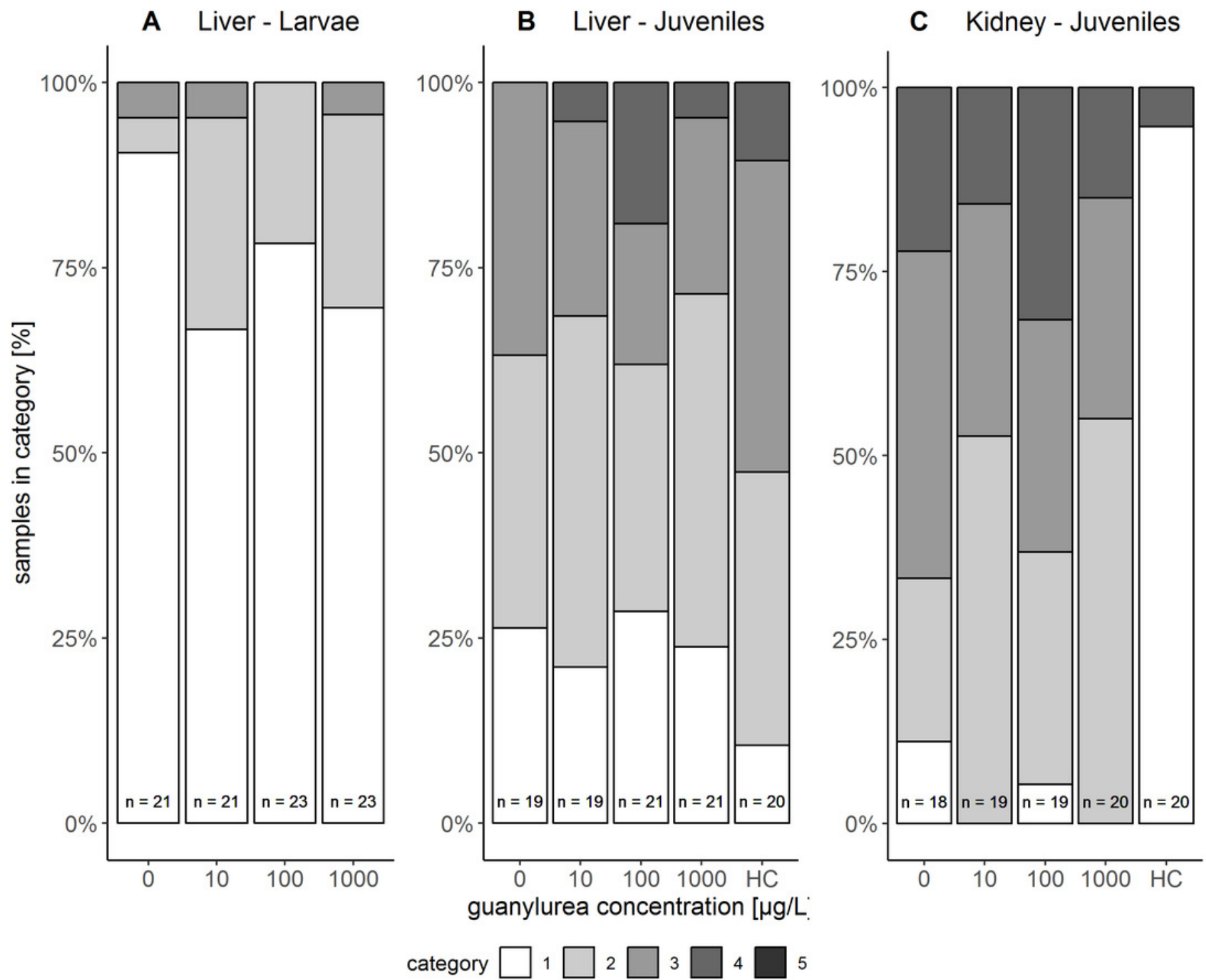


\section{Table $\mathbf{1}$ (on next page)}

Table 1 : Measured guanylurea concentrations in medium and in tissue, mortality, biometric data, developmental and biochemical parameters of larval brown trout exposed to guanylurea.

All data are displayed as arithmetic means \pm standard deviations. The heart rate was only evaluated for the negative control and the highest guanylurea concentration. LoQ: 'limit of quantification', n.e.: 'not evaluated', bpm: 'beats per minute', dpf: 'days post fertilisation'. 


\begin{tabular}{|c|c|c|c|c|}
\hline $\begin{array}{l}\text { Nominal water } \\
\text { concentrations }[\mu \mathrm{g} / \mathrm{L}]\end{array}$ & 0 & 10 & 100 & 1000 \\
\hline $\begin{array}{l}\text { Measured (real) water } \\
\text { concentrations }\end{array}$ & $<\operatorname{LoQ}$ & $9.0 \pm 0.9 \mu \mathrm{g} / \mathrm{L}$ & $117.3 \pm 5.3 \mu \mathrm{g} / \mathrm{L}$ & $1254 \pm 33 \mu \mathrm{g} / \mathrm{L}$ \\
\hline $\begin{array}{l}\text { Internal concentration } \\
\text { (average for } 3 \\
\text { replicates) }[\mathrm{ng} / \mathrm{g}]\end{array}$ & $<$ LoQ & $<$ LoQ & $<$ LoQ & 10.65 \\
\hline Mortality [\%] & $5.6 \pm 1.6$ & $2.2 \pm 3.1$ & $6.7 \pm 2.7$ & $3.3 \pm 0.0$ \\
\hline Time to hatch (dpf) & $55.5 \pm 3.0$ & $56.8 \pm 1.6$ & $57.0 \pm 1.1$ & $56.2 \pm 2.1$ \\
\hline Heart rate [bpm] & $59.2 \pm 5.1$ & n.e. & n.e. & $59.4 \pm 4.3$ \\
\hline Body weight [g] & $0.50 \pm 0.11$ & $0.50 \pm 0.14$ & $0.51 \pm 0.13$ & $0.50 \pm 0.12$ \\
\hline Body length [cm] & $3.8 \pm 0.3$ & $3.7 \pm 0.3$ & $3.8 \pm 0.3$ & $3.7 \pm 0.3$ \\
\hline $\begin{array}{l}\text { Condition factor } \\
{\left[\mathrm{g} / \mathrm{cm}^{3}\right]}\end{array}$ & $0.92 \pm 0.10$ & $0.94 \pm 0.09$ & $0.92 \pm 0.11$ & $0.99 \pm 0.11$ \\
\hline $\begin{array}{l}\text { Lipid peroxide level } \\
\text { [CHP-equiv./mg wet } \\
\text { weight] }\end{array}$ & $18.01 \pm 5.57$ & $16.97 \pm 4.61$ & $18.55 \pm 7.14$ & $19.48 \pm 5.24$ \\
\hline
\end{tabular}




\section{Table 2 (on next page)}

Measured guanylurea concentrations in medium, mortality, biometric data, biochemical and behavioural parameters of juvenile brown trout exposed to guanylurea.

All data are displayed as arithmetic means \pm standard deviations. LoQ: 'limit of quantification'. 


\begin{tabular}{|c|c|c|c|c|c|}
\hline $\begin{array}{l}\text { Nominal water } \\
\text { concentrations }[\mu \mathrm{g} / \mathrm{L}]\end{array}$ & 0 & 10 & 100 & 1000 & Hatchery control \\
\hline $\begin{array}{l}\text { Measured (real) water } \\
\text { concentrations }[\mu \mathrm{g} / \mathrm{L}]\end{array}$ & $<$ LoQ & $11.8 \pm 0.2$ & $132.5 \pm 2.4$ & $1319 \pm 60$ & - \\
\hline Mortality [\%] & $3.3 \pm 4.7$ & $3.3 \pm 4.7$ & $0.0 \pm 0.0$ & $0.0 \pm 0.0$ & - \\
\hline Body weight [g] & $2.80 \pm 1.01$ & $2.88 \pm 0.83$ & $2.83 \pm 0.88$ & $3.06 \pm 0.80$ & $8.66 \pm 2.64$ \\
\hline Body length [cm] & $6.4 \pm 0.7$ & $6.5 \pm 0.7$ & $6.5 \pm 0.7$ & $6.6 \pm 0.6$ & $9.1 \pm 0.8$ \\
\hline $\begin{array}{l}\text { Hsp } 70 \text { level [relative } \\
\text { grey value] }\end{array}$ & $1.15 \pm 0.18$ & $1.10 \pm 0.20$ & $1.18 \pm 0.18$ & $1.08 \pm 0.21$ & $1.09 \pm 0.07$ \\
\hline $\begin{array}{l}\text { Total distance moved } \\
{[\mathrm{cm}]}\end{array}$ & $781.5 \pm 786.2$ & $1432.7 \pm 1016.4$ & $972.0 \pm 452.0$ & $912.3 \pm 658.6$ & - \\
\hline Mean velocity $[\mathrm{cm} / \mathrm{s}]$ & $0.7 \pm 0.7$ & $1.3 \pm 0.9$ & $0.9 \pm 0.4$ & $0.8 \pm 0.6$ & - \\
\hline
\end{tabular}

2 